\title{
Fully Automated Classroom Attendance System
}

\author{
https://doi.org/10.3991/ijim.v13i08.10100
}

\author{
Eid Al Hajri, Farrukh Hafeez ${ }^{(凶)}$, Ameer Azhar N V \\ Jubail Industrial College, KSA \\ farrukhhafeez $82 @$ hotmail.com
}

\begin{abstract}
This paper is based on the study and the implementation of the pilot project for customized, automated, highly secured class room management system known as fully automated classroom attendance system. In this research paper, the strategies, design, development and implementation of a pilot project for class room attendance management systems is explained in detail. As a pilot project, mobile app is built on Android platform using Xamarin programming. Prototype of proposed system provides high level of authentication by embedding face recognition and biometric verification together with radio frequency identification system (RFID) system. Though given model features are specially designed for our college needs, but this model can be modified for general usage and can be applied for all academic levels i.e. school, college, universities. Among the other features of system, one important feature is selection of system to work in smart mode in which system closes after predefined time.
\end{abstract}

Keywords-USB RFID proximity sensor, RFID Cards, attendance management system, mobile application, smart mode system, face recognition, thumb verification.

\section{Introduction}

In recent time, technology trend is to switch from typical traditional system to fast, smart and interactive system which can be linked to some web application, so that users can access the system at any place at any time. Radio frequency identification system abbreviated generally as RFID has proven its self-one of the secured, inexpensive and fast emerging technology. RFID application area includes access management, location based services, smart homes, airports, super markets, tracking vehicles for road pricing and speed controlling [1-4]. This technology transformation of system into RFID system has been adopted in attendance systems and different models have been proposed [5].In some models, RFID system is integrated with fingerprint [6].In some models along with RFID, other parameters like face recognition are also applied [8].In most of the systems models, focus is on systems which can detect false and bogus attendance, an undeniable requirement, but in this paper a system model is proposed which can be able to do pre and post attendance requirements, the proposed system model implementation is based on Jubail Industrial college defined protocols for student attendance, and the system is able to address and comply all college procedures related to student attendance smoothly and efficiently. With recent advance- 
ment and technology trend toward IOT, it is preferable that system should be able to access anywhere at any time.

\section{Background}

In this section college rules regarding student attendance system are discussed. As like most of academic intuition, academic semester consist of sixteen weeks, before starting classes, faculty member prepare their attendance file, contains all student list for both theory and lab. For attendance teacher call students name one by one and mark their attendance in a paper. The students coming after certain minutes (in Jubail Industrial College 3 minutes) are considered late and students coming after five minutes are considered marked as absent. All these steps are done manually. Teachers spend their valuable time for taking attendance and needed to be attentive to observe who is coming late or who is absent. In addition to that, if student goes outside classroom for some reason he should return within 5 minutes, in case if he takes more than 5 minutes he will be marked absent for this period. Currently in JIC, after taking the attendance manually, the teacher will be entering the attendance manually to a data base known as SIS (Students Information System). In the Proposed system, each student will be issued a separate RFID card, or a RFID tag can be embedded in the existing student ID card. The students are supposed to come with RFID cards to the classroom. For avoiding using of card by other student every RFID card is linked with database, where student biometric thumb impression and face recognition can be verified by using designed app options. Implementation of the idea proposed in this paper enhances the competitiveness in the current world of IOT. As a pilot model mobile app is designed named "JIC CMS". Jubail Industrial College Class Room Management System.

\section{System Design}

In the whole scenario explained above, it was required to design such an efficient and smart system which would be able to solve all problems is required. For this an RFID based system with specially designed app has been developed. App name is "JIC CMS", Jubail Industrial College Classroom management system. This app is designed on Xamarin platform. In our designed system every faculty member will have its RFID Reader and mobile with installed application. Technical detail of RFID reader is mentioned in table 1.The operation of App starts from staff account generation which includes staff personal details, department details etc. App screen shot is shown in Fig 1. After creation of account new window with three options will be available, Enrolment, Attendance and Report as shown in Fig 2 
Table 1. RFID Reader Specification

\begin{tabular}{|l|l|}
\hline \multicolumn{1}{|c|}{ Specification } & \multicolumn{1}{c|}{ Specification Value } \\
\hline Supply Voltage & DC 5V \\
\hline Maximum working current & $<10 \mathrm{~mA}$ \\
\hline Card sensing speed & less than 200ms \\
\hline Encoding & Manchester 64 -bit,modules 64 \\
\hline Operating temperature & $-10^{\prime} \mathrm{C} \sim+70^{\prime} \mathrm{C}$ \\
\hline Operating frequency & $125 \mathrm{KHZ}$ \\
\hline Baud rate & $9600 \mathrm{Kbit} / \mathrm{s}$ \\
\hline Support Card Type & EM4100, TK4100 \\
\hline Read Range & $5 \mathrm{~cm}$ \\
\hline Dimensions & $63 \times 18 \times 8(\mathrm{~mm})$ \\
\hline Output format & 10 digit decimal \\
\hline
\end{tabular}

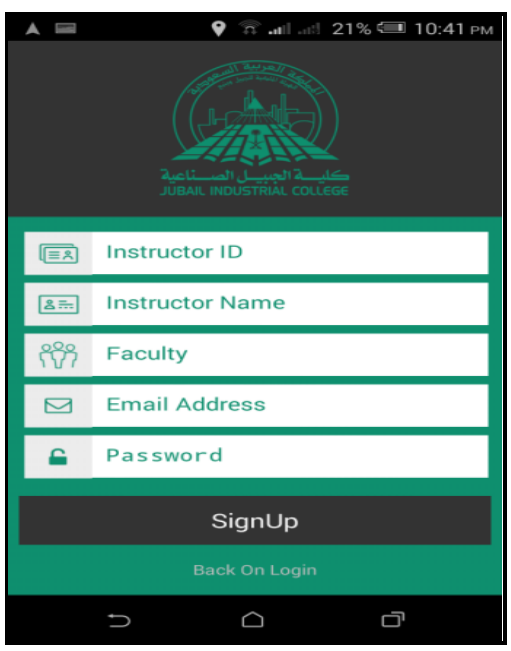

Fig. 1. Faculty Personal Information window screen shot

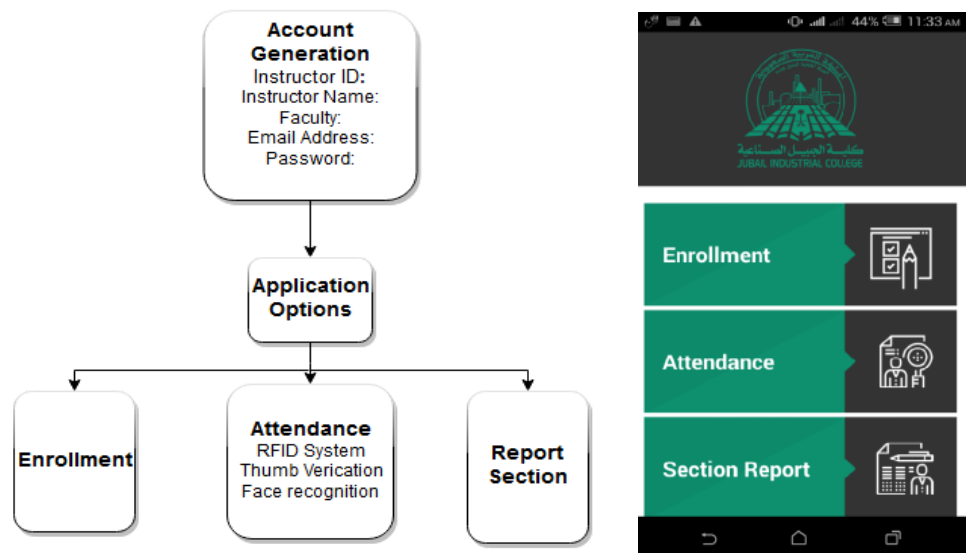

Fig. 2. JIC CMS App option 


\section{Enrolment Section}

In the enrolment screen teacher can upload the name of student, student id number, course details, activity details, section details etc. available at the beginning of the semester. This uploading should be done only once at the beginning of each semester for each course.

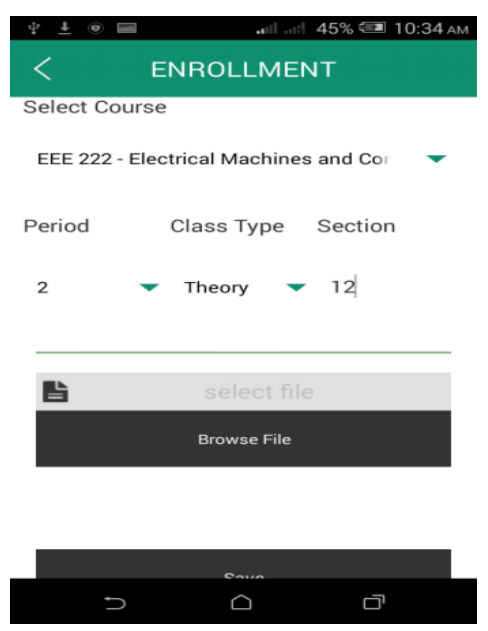

Fig. 3. Enrolment section screen shot

\section{$5 \quad$ Attendance Section}

In this section regular attendance system that is based on RFID is defined. For identification of bogus attendance and to provide higher level of verification thumb verification and face recognition can be embedded in customized mobile app in attendance section option. This bio metric identifiers verification is extremely applicable during examination for ensuring smooth conduction of exam. Details of implementation and working algorithms are also part of this section. Figure 4 shows flow chart of attendance section.

\subsection{RFID identification system}

In our designed system it is assumed that every faculty member will have its $125 \mathrm{KHZ}$ RFID Reader and mobile with installed application. Every student is provided with an RFID card. 10 digit unique card numbers are assigned to each RFID card. RFID Card number is mapped to student Identification number in RFID database. Low frequency $(125 \mathrm{KHz})$ is used which can be detected with RFID reader with distance of $5 \mathrm{~cm}$. Faculty member connect USB stick to his mobile and open app "JIC CMS" and open concerned section. As the students enter to the classroom mark their attendance by simply showing the RFID tag to the card reader, students can just keep 
the RFID in the line of sight distance. If the student comes within first " 3 " minutes, he will be detected and marked as present as shown in figure 5. After three minutes present option will convert automatically into late and will be valid for next two minutes, within this duration i.e. Three- five minutes system will be marked as late entry. Similarly according to the college rules a student coming after five minutes will be treated as an absent as shown in figure 6. All this features are implemented by linking the student entry to the system clock.

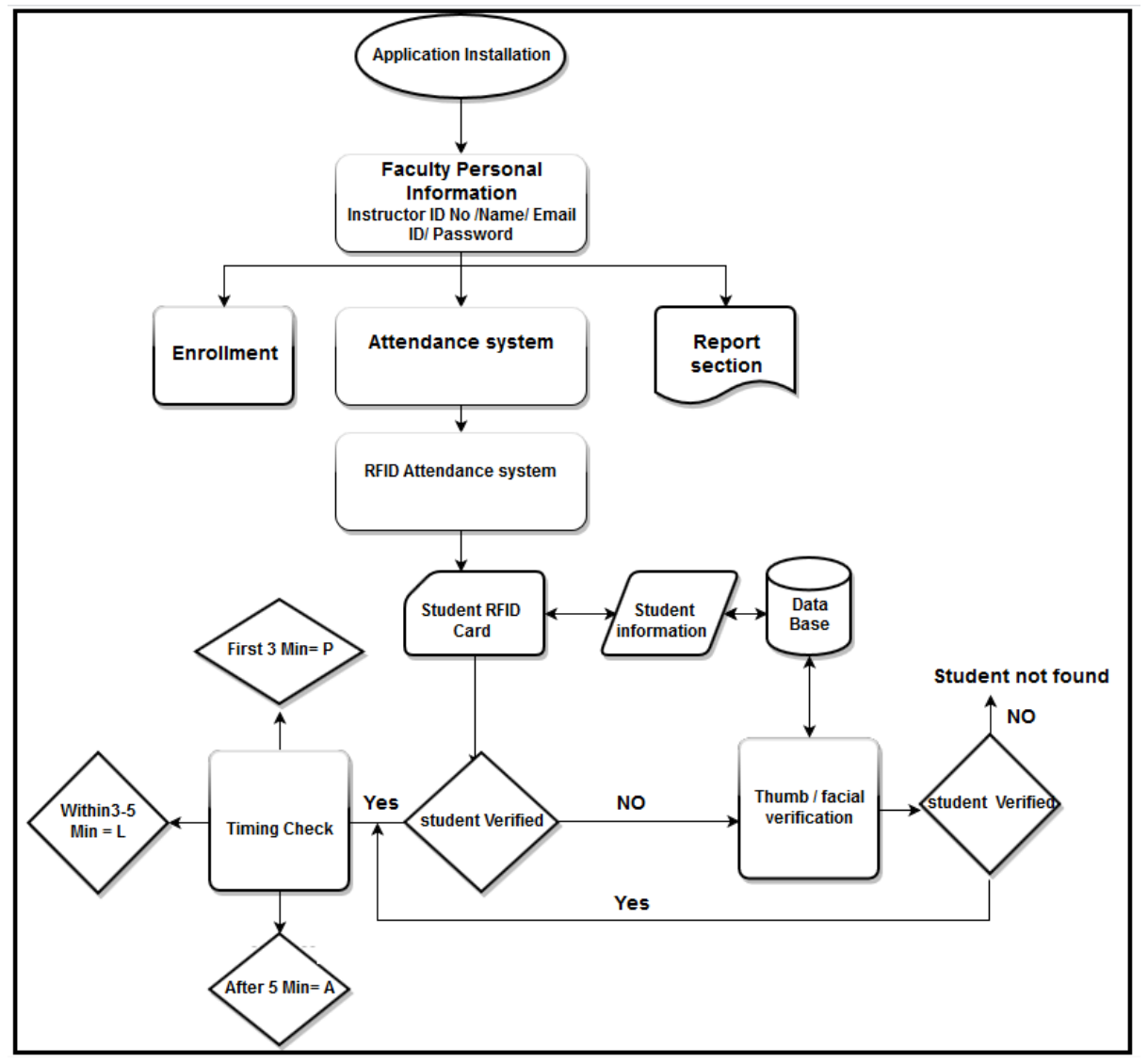

Fig. 4. Attendance section flow chart 


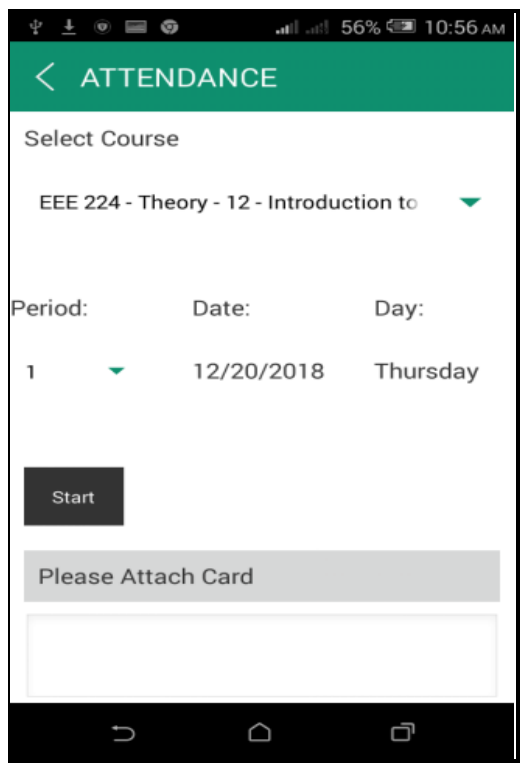

(a)

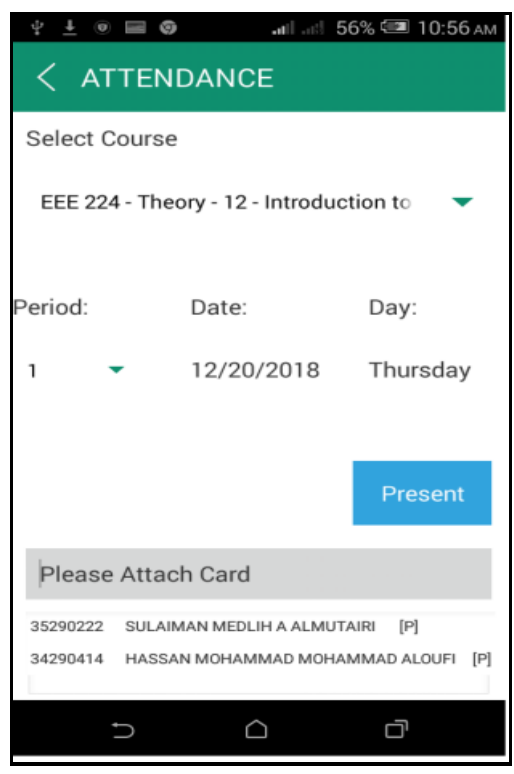

(b)

Fig. 5. Automatic Attendance system Screen shot (a) Before pressing start (b) Within "3" Minutes Marking Present

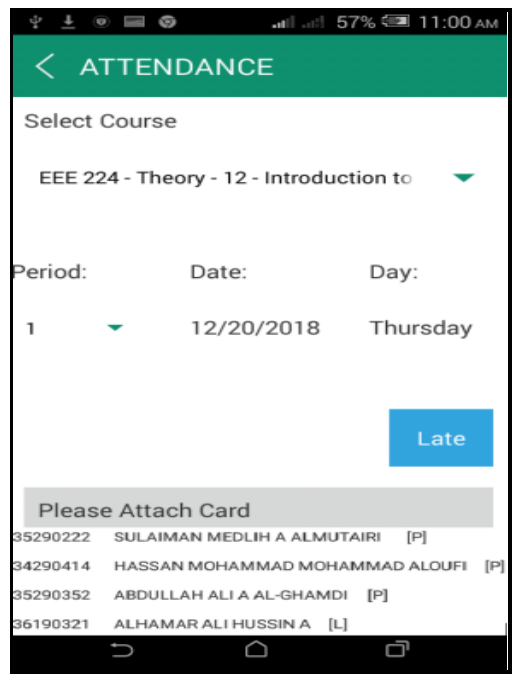

(c)

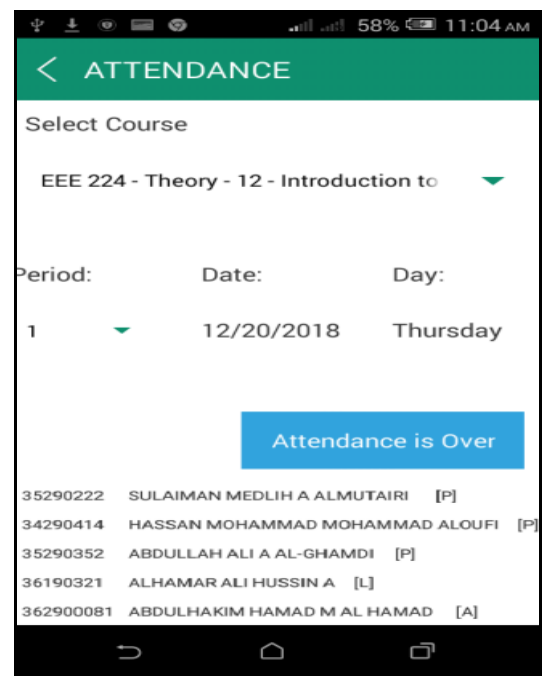

(d)

Fig. 6. Automatic Attendance system Screen shot (c) Between"3-5” Minutes Marking Late (d) After " 5 " Minutes Marking Absent 


\subsection{Thumb verification system}

In this section implementation of thumb verification system together with working algorithm used in mobile app designed by Xamarin will be discussed. Framework of biometric authentication system is shown in Figure 7. At the time of admission, student thumb templates are extracted and stored into the database. During the thumb verification process, using app option the system applies the same technique for thumb matching process. After matching thumb impression system generates student details like ID no, student picture, can be seen in screenshot on figure no 8 .

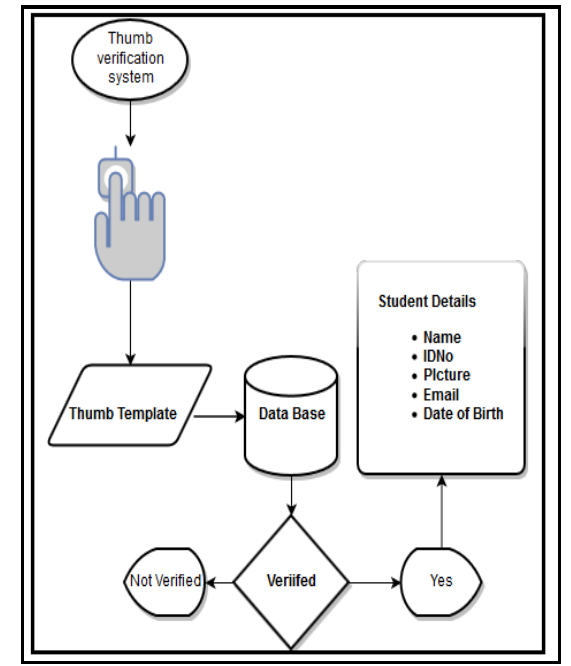

Fig. 7. Thumb Verification flow chart Fig. 8. biometric impression Screen shot

Regional sliding Technique: Selection of correct template on touch screen mobile devices is one of the important aspects. There are several difficulties like unconscious slipping of finger while pressing, occlusion of thumb more than the target size, etc. Substantial research shows that target size which is one of the critical factors affects user, must be near to $9.6 \mathrm{~mm}$. Although number of techniques like tap tap, shift, thumb pace, escape are available. In all these techniques named before have issues of targeting not only the selected area but also surrounding area. Based on these facts designed and implemented our app on Regional sliding technique for sensing and target selection during target selection. Research shows Regional sliding performs in shorter time with lowest mean error rate and also less effected on small target. Fig. 9 shows comparative analysis of Regional sliding with shift and Tap Tap techniques as stated in [16]. 


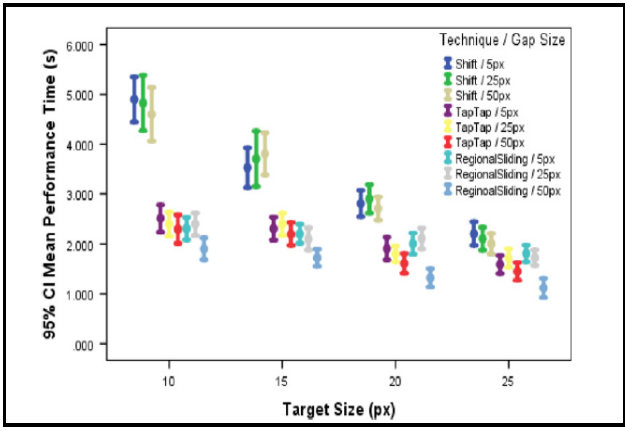

(a) Mean performance time

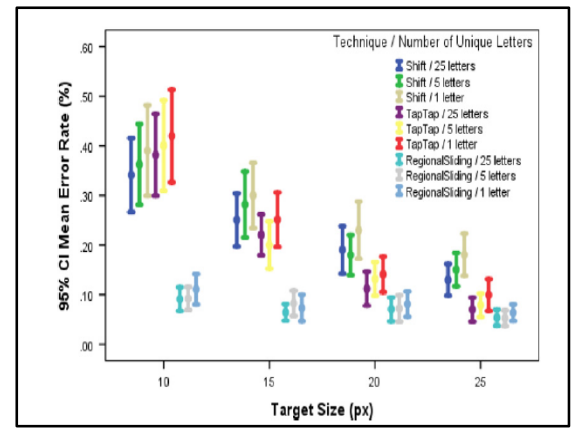

(b) Mean Error rate

Fig. 9. (a) Mean performance time (b) Mean Error rate

Face verification system: To provide higher level of security, face verification option is selected. It is assumed at the time of admission and enrollment high quality image has been stored in data base for verification purpose. For face verification in real time it was required to implement some algorithm. Face Recognition process consist of face detection, preprocessing and finally application of any face Recognition algorithm. Face detection is implemented by using HOG, histogram of oriented gradients algorithm. Typical steps involved are defined in block diagram figure no 10

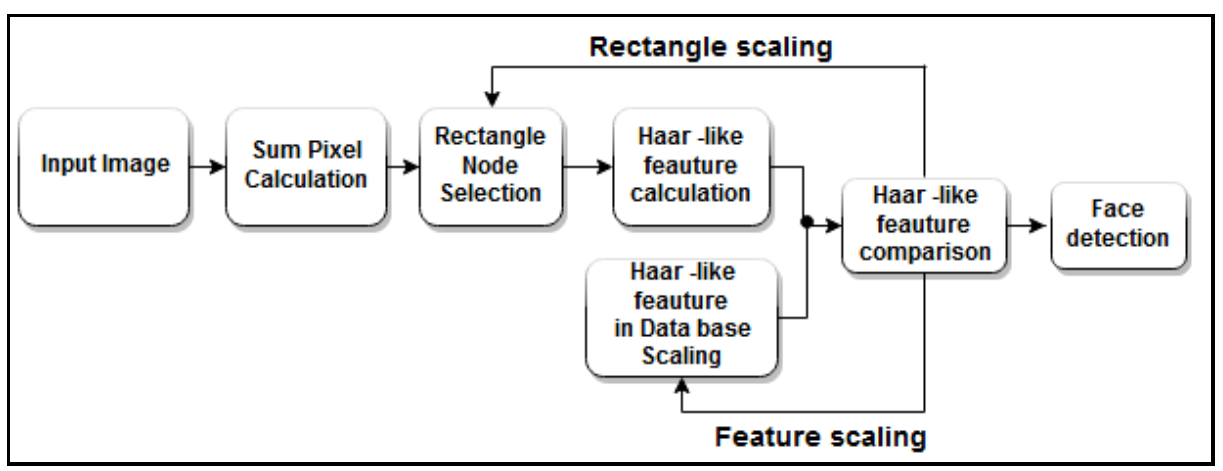

Fig. 10.Block Diagram of Histogram of oriented gradients algorithm

Selection and application of suitable face detection algorithm was one of the prime task. In smart phones either android or IOS platform based, face detection implementation is easy after the availability of open CV. Open CV (Open Source Computer Vision) is an open source library for image processing and computer vision, originally developed by Intel and free for both commercial and non-commercial use. The face recognition is made easy by the Face Recognizer in Open CV. Figure 11 shows comparison of different algorithm .Substantial research shows all algorithms are relative accurate but open face shows more accurate and results are more reliable over other available algorithms. Open face is based on deep convolutional networks (CNNs) 
technique. Figure 12 shows implementation of open face using CNNs. Figure 12 is divided into two parts. Left side is using for extraction of features, needed to perform only once. On the right side images are extracted from dlib's pre trained detector working on HOG algorithm, after certain pre-processing send to convolutional neural network. CNN use these features which are obtained from deep neural network, for predicting person image is passed through right part, and the person classification will be given out.

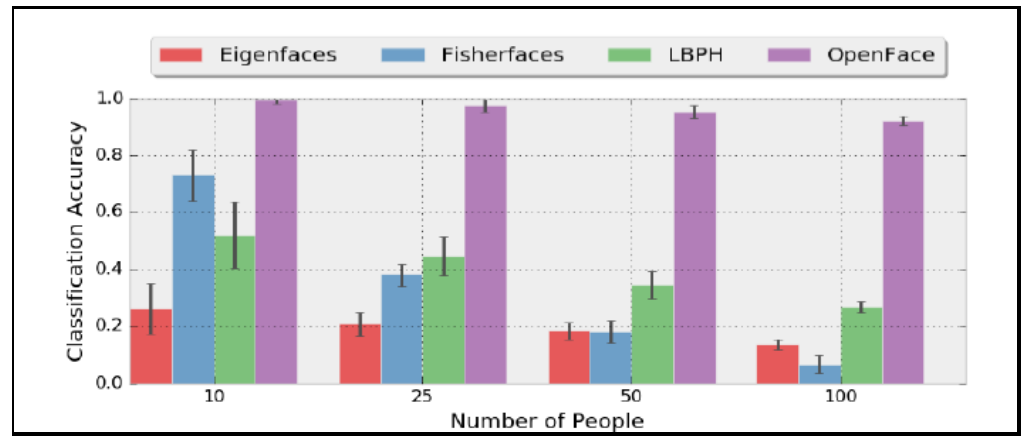

Fig. 11.Comparison of Open face and other algorithm [XII]

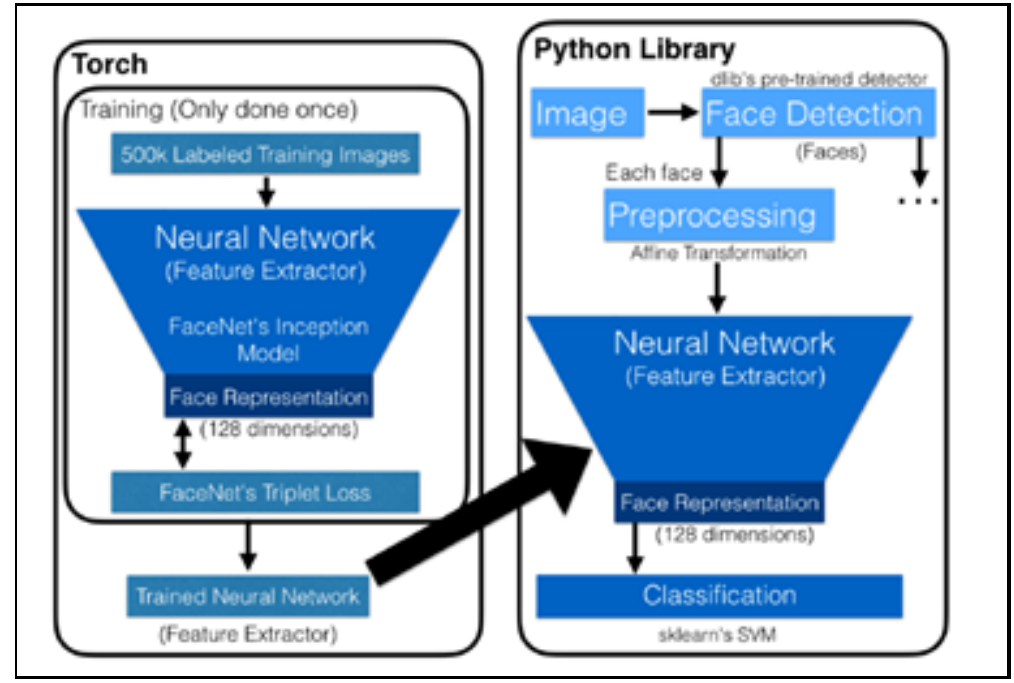

Fig. 12.Open Face's project structure (B, AmosAmos, B., LB.,, 2016) 


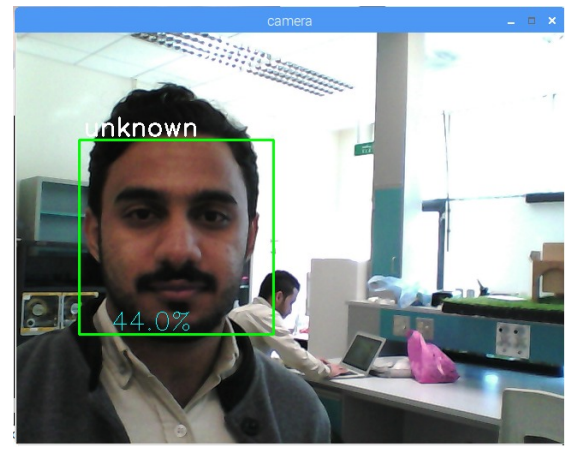

(a)

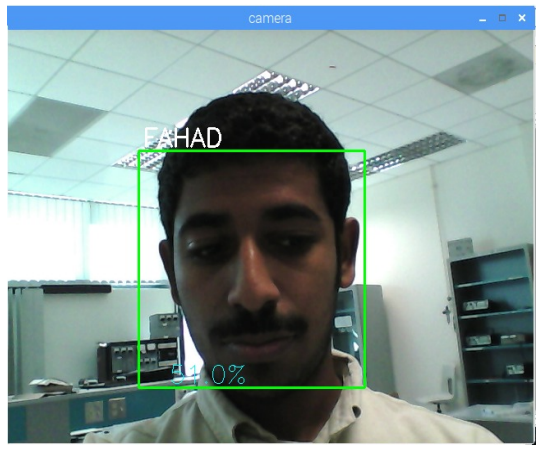

(b)

Fig. 13.Face Recognition using open CV for JIC CMS: (a) 44\% accuracy Unknown (b) $51 \%$ accuracy Recognized

\section{Report Section}

In this option of JIC CMS app any students Presence reports (weekly, monthly or for any specific duration) can be seen. In addition to report generation, special privilege option is available to perform manual modification in case of special need.

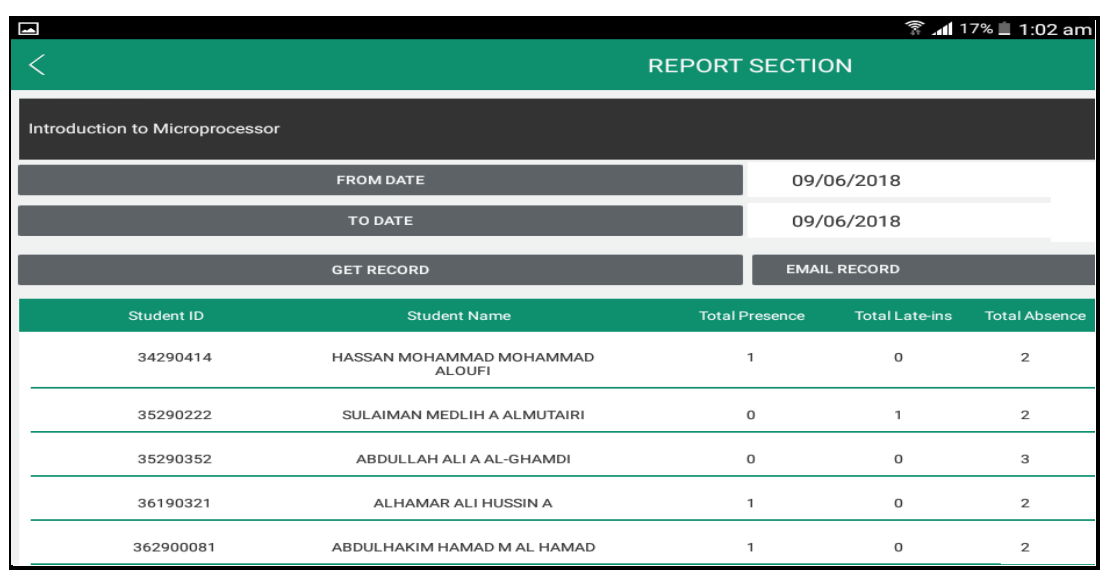

Fig. 14.Screen Shot of Report Section.

\section{Conclusion}

The implemented system offers number of befits over traditional system includes freedom of delivering lecture with full focus without notifying student timing. As it is fully automated, the chance of error in the attendance entry is NIL. Options of bio- 
metric identification make system invincible. Although designed app options are customized to college rules but concept of application is applicable to any academic level or organizational level. Application of thumb/ face recognition reduce misuse of RFID card. Linking this app with student information, which student use to see their attendance, will drastically save faculty time and resources as well.

\section{Future Work}

Although proposed model gives an idea of smart class but still improvement place is there. RFID reader range can be increased by replacing high range RFID reader. During our study of this project it was found that instead of using Xamarin, using of other mobile development tools like Ionic, React Native will lead to better application result at the cost of time and resources.

\section{References}

[1] Barenji, A. V., \& Değirmenci, C. (2015). Robot Control System based on Web Application and RFID Technology. MATEC Web of Conferences, 28, 04001. https://doi.org/10. $\underline{1051 / \mathrm{matec} c o n f / 20152804001}$

[2] Chen, X., Yu, J., Yao, Y., Wang, C., \& Valderas, D. (2014). RFID Technology and Applications. International Journal of Antennas and Propagation, 2014, 1-1. doi:10.1155/2014/ 184934

[3] Fescioglu-Unver, N., Choi, S. H., Sheen, D., \& Kumara, S. (2014). RFID in production and service systems: Technology, applications and issues. Information Systems Frontiers, 17(6), 1369-1380. https://doi.org/10.1007/s10796-014-9518-1

[4] Qiu, Y., Zhou, L., \& Zhu, Q. Y. (2013). A Case Study for High-Level Course Website Development Based on RFID and Face Recognition. Applied Mechanics and Materials, 411414, 458-461. https://doi.org/10.4028/www.scientific.net/amm.411-414.458

[5] HaMyat Nwe, T. M. (2015). Students' Attendance Management System Based On RFID And Fingerprint Reader. International Journal of Scientific \& Technology Research.

[6] Cui, L., Zhang, T., Zhang, H., Wang, L., \& Wang, F. (2017). Design of Attendance Check System Based on Ethernet Technology and Fingerprint Recognition. DEStech Transactions on Economics, Business and Management, (Emem). https://doi.org/10.12783/dtem/emem $\underline{2017 / 17088}$

[7] Lee, W., Choi, J., \& Lee, D. (2017). Comparative Performance Analysis of Anticollision Protocols in RFID Networks. RFID Handbook, 161-180. https://doi.org/10.1201/97814200 $\underline{55009 . \operatorname{ch} 9}$

[8] Qiu, Y., Zhou, L., \& Zhu, Q. Y. (2013). A Case Study for High-Level Course Website Development Based on RFID and Face Recognition. Applied Mechanics and Materials, 411414, 458-461. https://doi.org/10.4028/www.scientific.net/amm.411-414.458

[9] Rfid Based Attendance System. (2017). International Journal of Recent Trends in Engineering and Research, 3(4), 94-97. https://doi.org/10.23883/ijrter.2017.3114.wjkh4

[10] Video-BasedfaceRecognition. (n.d.).SpringerReference.doi:10.1007/springerreference_730 82 
[11] Alsmirat, M. A., Al-Alem, F., Al-Ayyoub, M., Jararweh, Y., \& Gupta, B. (2018). Impact of digital fingerprint image quality on the fingerprint recognition accuracy. Multimedia Tools and Applications, 1-40. https://doi.org/10.1007/s11042-017-5537-5

[12] Chun Yu, W. Y. (2017). RegionalSliding: Facilitating small target selection with marking menu for one-handed thumb use on touchscreen-based mobile devices (Vol. 17). Amsterdam,: Elsevier Science B. V. A. https://doi.org/10.1016/j.pmcj.2014.02.005

[13] Fabio Roli, L. L. (2014). Analysis of unsupervised template update in biometric recogntion systems (Vol. 37). New York, USA: Elsevier Science. doi:10.1016/j.patrec.2013.05.021

[14] Iloanusi, Ogechukwu N (2016). Effective statistical-based and dynamic fingerprint preprocessing technique (1st ed., Vol. 6). IET Biometrics. https://doi.org/10.1049/iet-bmt.2015.0 064

[15] Amos, B., Ludwiczuk, B., \& Satyanarayanan, M. (2016). OpenFace : A general- purposeface recognition library with mobile applications.

[16] N. (2017). A Comparriosn of faical recognizaition algortitham. Bachelour Thesis Degree program in BIT.

[17] H. (2013). Comparison of different algorithm for face Recogizaiotn (9th ed., Vol. 13,Ser. 10). GLobaol Journal Inc (USA).

\section{Authors}

Eid Al Hajiri is currently the Managing Director of Jubail Industrial College. He obtained his Bachelor degree in Electrical Engineering from Purdue University. He received his Masters and $\mathrm{PhD}$ from University of Sheffield in Process Safety Engineering, Automatic Control \& Systems Engineering respectively. He has large years of industrial and academic experience in Saudi Aramco Company, SABIC, Jubail Industrial College etc. He obtained many certifications related to instrumentation and control engineering, education etc. He published many papers in international publications. His research interest include Advanced Robotics and Automation in industry and academics, Academic-Industry Collaboration and Industrial Cluster Management

Farrukh Hafeez is working as a Lecturer of Instrumentation and Control Engineering Technology at Jubail Industrial College. He received his B.E. degree in Electronics and M.E degree in Industrial control System from NED University of Engineering \& Technology Karachi, Pakistan in 2005 and 2009 respectively. His research interest include control system design and applications.

Ameer Azhar has more than 27 years of experience in various universities and colleges in India, Sultanate of Oman, United Arab Emirates and Kingdom of Saudi Arabia. Currently he is working as a Senior Lecturer of Instrumentation and Control Engineering Technology at JIC. He received his B.Tech. Degree in Electronics and Communication Engineering and M.Tech degree in Computer Science and Engineering from University of Calicut. His areas of interest include microprocessors, microcontrollers, computer control, industrial control and computer algorithms.

Article submitted 2019-01-06. Resubmitted 2019-04-11. Final acceptance 2019-05-24. Final version published as submitted by the authors. 